\title{
UMA ANÁLISE DAS CONCEPÇÕES TEÓRICAS SOBRE QUALIDADE DA EDUCAÇÃO NA AMÉRICA LATINA A PARTIR DE PUBLICAÇÕES DA UNESCO (1966-2008)
}

\author{
E. L. H. TAVARES ${ }^{1}$, B. CORSETTI ${ }^{2}$ \\ Universidade do Vale do Rio dos Sinos \\ pro.edson@gmail.com ${ }^{1}$
}

Artigo submetido em 28/03/2016 e aceito em 12/03/2019

DOI: $10.15628 /$ holos.2019.4332

\section{RESUMO}

A qualidade da educação vem sendo objeto de pesquisas pela Organização das Nações Unidas para a Educação, a Ciência e a Cultura - UNESCO, especialmente, a partir dos anos 1990, associada intimamente ao projeto de "Educação Para Todos - EPT" e identificada como um direito humano fundamental. Analisamos concepções teóricas sobre a qualidade da educação na América Latina, a partir de publicações da UNESCO, entre 1966 e 2008, através da metodologia histórico-crítica. Nosso objetivo principal neste trabalho foi apresentar concepções teóricas sobre qualidade da educação que se destacaram nas pesquisas da UNESCO sobre a América Latina. Podemos evidenciar nas publicações da UNESCO e dos seus órgãos regionais, as influências dos paradigmas positivista, do comportamentalistabehaviorista e da pedagogia das competências, preferindo uma concepção sobre a qualidade da educação através de uma forma operacional (de dimensões) e de indicadores. Constatamos, também, que a maior parte das concepções teóricas sobre a qualidade educacional latino-americana prescinde de uma base filosófica na sua definição conceitual.

PALAVRAS-CHAVE: Políticas educacionais, qualidade da educação, avaliação em larga escala, UNESCO, América Latina.

\section{AN ANALYSIS OF THEORETICAL CONCEPTS OF THE QUALITY OF EDUCATION IN LATIN AMERICA FROM UNESCO PUBLICATIONS (1966-2008)}

\begin{abstract}
Quality of education has been the subject of research by the United Nations Educational, Scientific and Cultural Organization (UNESCO), especially since the 1990s, closely associated with the "Education for All - EFA" project and identified as a Fundamental human right. The present study analyzes theoretical conceptions about the quality of education in Latin America, based on UNESCO publications, between 1966 and 2008, through historicalcritical methodology. The main objective of this work is to present theoretical conceptions about the quality of education that were highlighted in UNESCO researches
\end{abstract}

on Latin America. It is possible to find influences of the Positivism, Behaviorism, and the competency-based paradigms in the publications of UNESCO and its regional agencies. Thus, the preference for a concept of the quality of education through an operational form (dimensions) and indicators is observed in such publications. Ultimately, it is possible to see that most theoretical concepts of Latin American educational quality come in its conceptual definition from a philosophical base

KEYWORDS: Educational policies, quality of education, evaluation in large-scale, UNESCO, Latin America. 


\section{INTRODUÇÃO}

A qualidade da educação vem sendo objeto de pesquisas pela Organização das Nações Unidas para a Educação, a Ciência e a Cultura - UNESCO, identificada como um direito humano fundamental. A ampliação do acesso à educação, em nossa região, entre as décadas de 1950 e 1960; a centralidade da melhoria da qualidade da educação no Projeto Principal de Educação na América latina e Caribe, iniciado nos anos 1980; e uma literatura específica sobre o problema da qualidade educacional, contribuíram sobremaneira para o destaque atual desta temática. No início da década de 1990, a qualidade já era alçada à condição de grande problema da "crise da educação" (Risopátron, 1991, p. 14). A pesquisadora identificou diversas concepções teóricas sobre a qualidade da educação destacadas na América Latina; porém, afirmava:

[...] são escassos os trabalhos que tentaram esclarecer o seu significado e menos ainda os que tiveram êxito em alcançá-lo. O problema que enfrentamos hoje é um problema teórico: a construção de significados que contribuam para uma maior precisão ao conceito de qualidade e melhoria da mesma. $\mathrm{O}$ anterior em entendimento de que uma maior clareza sobre o que entendemos por qualidade permitirá, por sua vez, agir sobre o melhoramento dela. ${ }^{1}$

A constatação daquela realidade, complexa, no princípio dos anos 1990, ainda, hoje, aguça nossa intenção de abordar o debate sobre as concepções teóricas sobre a qualidade da educação. Analisamos publicações da UNESCO, entre 1966 e 2008; em especial, aquelas referentes aos seus órgãos regionais que se dedicam a pesquisar a realidade educacional latino-americana como: a OREALC Santiago - Oficina Regional da Educação da América Latina e Caribe e o LLECE Laboratório Latino-americano de Evolução da Qualidade da Educação.

Nossa perspectiva teórico-metodológica, parte da idéia de que os fenômenos materiais e espirituais estão permanentemente em movimento e se transformando. Para investigá-los, definimo-nos por uma visão epistemológica dialética e uma metodologia histórico-crítica. Assim, consideramos que:

[...] A metodologia histórico-crítica busca compreender a questão educacional a partir do desenvolvimento histórico objetivo. Isso significa compreender a educação no contexto da sociedade humana, e como ela está organizada e como ela pode contribuir para a transformação da sociedade (Corsetti, 2010, p. 89).

\footnotetext{
${ }^{1}[\ldots]$ son escasos los trabajos que han intentado precisar su significado y menos aún los que han tenido êxito em lograrlo. El problema que enfrentamos hoy es um problema teórico: la construccion de significados que contribuyan a otorgale uma mayor precisión al concepto de calidad y al mejoramiento de la misma. Lo anterior em el entendido de que uma mayor claridad acerca de lo que entendemos por calidad permitirá, a su vez, actuar sobre el mejoramiento de ella. (RISOPÁTRON, 1991, p. 14).
} 


\section{CONTEXTO HISTÓRICO DA ATUAL REALIDADE EDUCACIONAL}

Estamos numa nova fase do modo de produção capitalista, mundial. "A globalização caracteriza o atual período de evolução do sistema capitalista [...] com manifestações na economia, na política, nas atividades culturais e nos comportamentos sociais [...] tem sua base material na terceira revolução tecnológica" (GORENDER, 1995, p. 93); iniciada após a II Guerra Mundial e universalizada a partir da Queda do Muro de Berlim, em 1989, e do fim da União Soviética - URSS, em 1991, e que avançou com a informática, as telecomunicações, a biotecnologia, a invenção de novos materiais, etc.

A política desta nova fase capitalista globalizada é representada pelo neoliberalismo, que também "nasceu logo após a II Guerra Mundial, na região da Europa e da América do Norte onde imperava o capitalismo. Foi uma reação teórica e política veemente contra o Estado intervencionista e de bem-estar" (ANDERSON, 1995, p. 09). Para os neoliberais, as raízes da crise do modelo econômico pós-guerra de 1973, segundo Anderson (1995): “[...] estavam localizadas no poder excessivo e nefasto dos sindicatos [...], que havia corroído as bases de acumulação capitalista com suas pressões reivindicativas sobre os salários e com sua pressão parasitária para que o Estado aumentasse cada vez mais os gastos sociais" (p. 10).

Como solução, os neoliberais, apesar de defensores de um Estado Mínimo, pregavam a manutenção de um Estado forte para romper o poder dos sindicatos, controlar e diminuir os gastos sociais, sendo que a estabilidade monetária era sua principal meta. As soluções propostas pelos neoliberais criaram um alto nível de desemprego, aplastaram greves, criaram uma nova legislação antissindical e cortaram gastos sociais; por fim, lançaram um amplo programa de privatização. A aplicação da receita neoliberal solapou inúmeros direitos sociais conquistados pela classe trabalhadora ao longo do século passado. Assim, estas reformas estruturais neolibera is, ancoradas no Estado mínimo, terminaram por diminuir o atendimento aos direitos sociais e humanos, conjugando uma estratégia que envolvia desregulamentação, descentralização e privatização.

Na década de 1990, especificamente na educação, a influência da Organização das Nações Unidas para a educação, a ciência e a cultura - UNESCO foi suplantada pelo Banco Mundial - BM. Isto fazia parte da estratégia do "Consenso de Washington" na condução da educação latinoamericana ao ideário neoliberal. A base teórica neoliberal do "Consenso de Washington" foi quem definiu as reformas implantadas na América Latina.

Essas políticas que inicialmente tiveram de ser, de algum modo, impostas pelas agências internacionais de financiamento mediante as chamadas condicionalidades, em seguida perdem o caráter de imposição, pois são assumidas pelas próprias elites econômicas e políticas dos países latino-americanos. (SAVIANI, 2008, p. 428). 
A internacionalização de políticas educativas de organismos internacionais como a UNESCO, o Banco Mundial - BM e a Organização para a Cooperação e Desenvolvimento Econômico - OCDE, iniciaram na década de 1980, mas concretizaram-se principalmente nos anos 1990.

$\mathrm{Na}$ análise do projeto regional para a educação da UNESCO, a questão que sempre vai permear nossa visão diz respeito à natureza filosófica, aos objetivos, à metodologia e às finalidades deste projeto e, em especial, no que se refere à qualidade da educação na América Latina. Pois, na UNESCO também se refletiram as idéias neoliberais que defendem a implantação de lógicas de mercado na educação. Destacamos aqui, que defendemos uma educação de concepção socializante, da satisfação humana das suas necessidades materiais e espirituais, em contraponto às concepções educacionais neoliberais privatizantes e mercadológicas (GENTILI, 2009, p. 1074).

A UNESCO foi criada logo após a Segunda Guerra Mundial com o objetivo da promoção da paz e dos direitos humanos, com base na cooperação e solidariedade intelectual e moral da humanidade. Balizada por esses princípios, a UNESCO promoveu uma luta mundial pela disponibilização de um maior acesso à ciência e à liberdade de expressão a todos, através da educação e da cultura.

\section{QUALIDADE DA EDUCAÇÃO NA AMÉRICA LATINA}

A UNESCO (1966, p. 32), já destacava uma preocupação com a qualidade da educação na obra Educación y Desarrollo em América Latina - Bases para uma Política Educativa, na qual:

[...] A extraordinária expansão quantitativa da educação em todos os níveis tem sido feito de forma súbita e ampla de uma só vez, o que obrigou a adotar soluções de emergência. Tem havido que improvisar professores, habilitar locais apressadamente e estabelecer escolas de duplo turno; a já crônica insuficiência de material de ensino se tem agravado; os serviços da administração educativa foram esmagados pelo das novas e crescentes responsabilidades que tinham que lidar. Todos estes fatores originados pela extensão da educação tem repercutido desfavoravelmente, sem dúvida, na qualidade da educação. ${ }^{2}$

A luta por uma melhoria da qualidade educacional latino-americana pautaria este organismo internacional ao longo de sua trajetória e, diversas ações foram realizadas, objetivando intervir nessa problemática. Em 1972, podemos encontrar uma das primeiras concepções teóricas

\footnotetext{
2 [...] la extraordinária expansión cuantitativa de la educación em todos sus niveles se ha realizado em uma forma súbita y amplia a la vez, que há obligado a adoptar soluciones de urgência. Há habido que improvisar profesores, habilitar locales apresuradamente y estabelecer escuelas de doble turno; la ya crônica insufiencia de material de enseñanza se há agravado; los servicios de la administración, educativa han sido desbordados por lãs nuevas y crecientes responsabilidades a que tenían que hacer frente. Todos estos factores originados por la extensión de la educación han repercutido defavorablemente, sin duda, em la calidad de la educación. (UNESCO, 1966, p. 32).
} 
sobre a qualidade da educação no relatório da Comissão Internacional de Desenvolvimento da Educação, em que:

A comissão identificou o objetivo fundamental de mudança social como a erradicação da desigualdade e o estabelecimento de uma democracia eqüitativa. Conseqüentemente, relatou, 'a meta e o conteúdo da educação devem ser recriados, para viabilizar as novas características da sociedade e as novas características da democracia (Faure et al., 1972, p. xxvi). [...] A melhoria da qualidade da educação, afirmou, demandaria sistemas nos quais os princípios de desenvolvimento científico e modernização poderiam ser aprendidos de forma a respeitar os contextos socioculturais dos alunos. (UNESCO, 2005, p. 30).

Noutra publicação pela UNESCO, em 1974, intitulada Educar para o Futuro, Harry Passow escreveu um artigo denominado "Dez causas principais da desigualdade de oportunidades", afirmando que as chances de uma criança obter sucesso escolar eram diretamente relacionadas com sua realidade social. Esta relação era tão direta que o sistema educativo foi acusado de limitarse a uma mera seleção dos alunos, colaborando com a manutenção do status quo, ao invés de promover o desenvolvimento de talentos e aptidões individuais (UNESCO, 1974, p. 83).

A UNESCO reafirmaria seu compromisso humanitário, relacionando a análise sobre a qualidade da educação com a realidade social, cultural e econômica até os anos 1980. A partir da década de 1990, influenciada por uma nova etapa internacional do modo de produção capitalista marcada pela globalização neoliberal, a posição da organização viria a sofrer alterações. Logo, no início dos anos 1990, podemos perceber uma aproximação significativa com as idéias neoliberais do Banco Mundial - BM e da OCDE, no Informe Mundial Sobre La Educación:

[...] a educação básica deve centrar-se na aquisição e nos resultados efetivos da aprendizagem, em vez de prestar exclusivamente atenção para o fato de matricular-se, de participar, de forma continuada em programas de instrução e de obter o certificado final. Os enfoques ativos e participativos são particularmente válidos para garantir esta aquisição e permitir os alunos a realizarem plenamente suas potencialidades. Por isso, é necessário definir para cada programa educacional, níveis aceitáveis de aquisição de conhecimento, e implementar sistemas melhorados avaliação dos resultados. (UNESCO, 1991, p. 83). ${ }^{3}$

Este texto, editado em 1991, foi elaborado por uma Comissão Interinstitucional, composta por: UNESCO, Programa Nacional de Desenvolvimento das Nações Unidas - PNUD, Fundo das Nações Unidas para a Infância - UNICEF e pelo Banco Mundial, e se destinava à Conferência Mundial sobre a Educação Para Todos, em Jontiem, realizada em 1990. A qualidade da educação

\footnotetext{
${ }^{3}$ [...] la educación básica debe centrar-se em lás adquisiciones y los resultados efectivos del aprendizaje, em vez de prestar exclusivamente atención al hecho de matricularse, de participar de forma continuada em los programas de instrucción y de obtener el certificado final. Los enfoques activos y participativos son particularmente válidos para garantizar esta adquisición y permitir a los aprendices realizar plenamente sus potencialidades. De ahi que sea necesario definir para cada programa educativo, niveles aceptables de adquisición de conocimientos, y aplicar sistemas mejorados de avalución de los resultados. (UNESCO, 1991, p. 83).
} 
passou a ser avaliada por resultados de testes, medidores da aquisição da aprendizagem dos alunos. As relações analíticas com a realidade social e cultural começaram a perder o foco por parte da UNESCO, que passaria a observar a qualidade da educação através do rendimento escolar dos alunos. Desta forma, ingressamos numa espécie de homogeneização provocada pelas avaliações em larga escala, preterindo a diversidade dos universos escolares. Assim, em 1992, surgiu um Projeto Conjunto, entre UNESCO e UNICEF, de Monitoramento da Qualidade da Educação, que é significativo para observarmos algumas influências do Banco Mundial e OCDE, pois enfocava:

[...] específica e deliberadamente o rendimento da aprendizagem na educação fundamental, conforme definido em Jontiem. Seus principais objetivos são equipar os definidores de política e implementadores de linha de frente com as ferramentas conceituais e analíticas necessárias, e com os indicadores, para monitorar a qualidade de seus programas de educação fundamental, em geral, e do rendimento da aprendizagem, em particular. (CHINAPH, 2000, p. 01).

Risopátron em sua obra: "El concepto de calidad de la educacion" (1991), analisando a literatura da década de 1980, contribuiu significativamente com o debate sobre a qualidade educacional. Para a pesquisadora, o conceito de qualidade é um significante e não um significado, e o mesmo pode assumir múltiplos significados:

A qualidade é um valor que requer definir-se em cada situação e não pode ser entendido como um valor absoluto. Os significados que se lê atribuam à qualidade da educação depende da perspectiva social a partir da qual se faz parte, dos sujeitos que enunciam (professores ou pais de família ou agência de planejamento educacional, etc.) e, desde o lugar em que se faz (prática educativa ou planejamento ministerial, por exemplo). 0 conceito de qualidade, enquanto significante, é referência de significados historicamente produzidos e nesse sentido, é um conceito que não pode ser definido em termos essenciais ou absolutos; portanto, não é um conceito neutro. Não é concebível uma única definição de qualidade, dado que estão nela das tomadas sobre o sujeito, sociedade, vida e educação. Ao dar claro que o conceito de qualidade e só operar com ele, ele aparece como se fosse neutro e universal. No entanto, a definição da qualidade da educação implica serviço político, social e cultural de frente para o educacional. (p. 15). ${ }^{4}$

A autora constatou diversos conceitos de qualidade da educação nas diferentes concepções curriculares reguladoras das práticas educativas, mediadoras entre as definições políticas

\footnotetext{
${ }^{4}$ La calidad es um valor que requiere definir-se em cada situación y no puede entenderse como um valor absoluto. Los significados que se lê atribuyan a la calidad de la educación dependerán de la perspectiva social desde la cual se hace, de los sujetos que la enunciam (profesores o padres de família o agencia de planificación educativa, etc.) y desde el lugar em que se hace (práctica educativa o planificación ministerial, por ejemplo). El concepto de calidad, en tanto significante, es referente de significados históricamente producidos y em esse sentido es um ceoncepto que no puede definirse em términos esenciales ni absolutos; por tanto, tampoco es um concepto neutro. No es pensable una sola definición de calidad, dado que subyacen en ella lãs que se adopten acerca de sujeto, sociedad, vida y educación. Al dar supuesto el concepto de calidad y solo operar com él, este aparece como si fuera neutro y universal. Sin embargo, la definición de la calidad de la educación conlleva posicionamento político, social y cultural frente a lo educativo. (RISOPÁTRON, 1991, p. 15).
} 
educacionais e os seus processos. Risopátron analisou as ideologias da eficiência social e da reconstrução social.

A ideologia da eficiência social, com raízes no positivismo e no pragmatismo, predominou entre os conceitos de qualidade da educação. Nesta ideologia, encontramos a base da teoria curricular da tecnologia educativa, calcada nas idéias de racionalidade técnica e de um currículo nacional visando o controle da eficiência do processo educativo, que definiria a qualidade da educação, através de metas administrativas objetivas e observáveis. A mudança do comportamento se configuraria como a essência da educação. Com isto, se investigaria os aspectos que influenciariam a qualidade da educação, numa idéia de que conhecer as partes permitiria o conhecimento do todo, bem como a medição objetiva do rendimento escolar (do produto). A eficiência interna se garantiria pela tecnologia educativa e eficiência externa na relação entre educação e ocupação no mercado. A qualidade da educação seria definida por intermédio da operação com variáveis e fatores de forma objetiva, na qual indicadores se traduziriam em comportamentos, condutas ou atitudes passíveis de observação e quantificação.

Por outro lado, para a autora, a ideologia da eficiência da reconstrução social sustentaria a teoria crítica do currículo, que compreende que a educação e sua qualidade estão social, cultural e politicamente determinadas. Definindo a qualidade da educação de acordo com as demandas educacionais das sociedades, especialmente, as locais. Esta conceituação histórico-social e cultural da qualidade educacional se opõe a uma definição neutra, universal, padronizada, a-histórica e atemporal. Desta maneira, o objetivo educacional seria a satisfação das necessidades sociais e culturais de uma determinada realidade social e a qualidade da educação evoluiria em relação às respostas do sistema educativo às demandas das comunidades.

O relatório Delors, da UNESCO de 1996 (2001, p.90), desenvolveu uma concepção teórica integrada e abrangente sobre a qualidade da educação, ao entender a educação ao longo da vida, com base nos quatro pilares: "aprender a conhecer, aprender a fazer, aprender a viver junto e aprender a ser". Em 2003, reafirmando seu papel fundacional, "[...] a UNESCO promove a educação de boa qualidade como um direito humano, e apóia uma abordagem baseada em direitos para todas atividades educacionais" (Pigozzi, 2004 apud UNESCO, 2005, p. 30).

As Conferências de Jontiem (1990) e de Dacar (2000) também tiveram destacada contribuição, com o enfoque de uma "Educação Para todos", no debate sobre a qualidade da educação: A Declaração de Jomtien, em 1990 e, em especial, o Marco de Ação de Dacar, em 2000, reconheceram a qualidade da educação como um fator primordial da realização de Educação para Todos" (UNESCO, 2005, p._29).

Em 2005, o Diretor Geral da UNESCO, Koïchiro Matsura, no prefácio do "Relatório de monitoramento global de EPT 2005: educação para todos: o imperativo da qualidade/UNESCO" (2005, p.01) defendeu que "a qualidade [da educação] deve ser analisada à luz da definição de cada sociedade sobre o objetivo da educação". Esta visão ampla, inicial, sobre a qualidade da educação foi reduzida, logo adiante, quando o mesmo finalizou sugerindo, com uma noção quase metafísica, propondo um consenso nacional sobre qualidade da educação. Se primeiramente, havia uma ligação da qualidade com os objetivos da educação de cada sociedade, no final, há uma redução desta concepção, na proposta de um possível consenso nacional sobre a qualidade da 
educação, numa sociedade capitalista neoliberal, globalizada, na qual as desigualdades são cada vez maiores.

Entre as metas lançadas pelo projeto "Educação Para Todos - EPT", a de número seis representaria a de qualidade. O Índice de Desenvolvimento de Educação Para Todos permitiu evidenciar que a meta da qualidade está mais desenvolvida nas regiões onde também se desenvolveram nas outras cinco metas: cuidados na primeira infância, educação primária universal, aprendizagem de jovens e adultos, alfabetização e gênero. No tocante aos testes internacionais de desempenho, o Relatório (2005) diz revelarem que o status socioeconômico influencia fortemente os resultados escolares, e por isso, as políticas econômicas e educacionais devem abordar as desigualdades socioeconômicas entre os alunos.

O Relatório na definição sobre a qualidade da educação destaca que:

As diversas abordagens à qualidade têm suas raízes em diferentes tradições de pensamento educacional. Abordagens humanistas, teoria behaviorista, críticas sociológicas da educação e desafios ao legado do colonialismo enriqueceram o debate sobre qualidade, e produziram visões distintas dos objetivos educacionais que devem ser alcançados. Para conciliar uma diversidade de abordagens, o Relatório adota uma estrutura que leva em consideração cinco fatores principais que afetam a qualidade: os alunos, cuja diversidade deve ser reconhecida; o contexto nacional econômico e social; os recursos materiais e humanos; o processo de ensino e aprendizagem; e os resultados e benefícios da educação. Ao focalizar essas dimensões e a maneira como interagem, é possível fazer um mapeamento para compreender, monitorar e aprimorar a qualidade (UNESCO, 2005, p. 17).

Destacam-se três princípios consensuais sobre qualidade da educação no "Relatório" de 2005: a necessidade de relevância, a equidade de acessos e resultados, e a observância adequada aos direitos individuais. Distinguem-se ainda, os resultados e os processos educacionais que conduzem à qualidade, diferenciando abordagens de critérios absolutos, de padronização fixa; de outras, relativistas, que enfatizam percepções, experiências e necessidades das pessoas envolvidas no processo de aprendizagem. Neste mesmo relatório, encontramos as seguintes dimensões na avaliação da qualidade da educação: a característica dos alunos; o aspecto contextual; os insumos facilitadores; ensino e aprendizagem; e os resultados.

Identificando as diferentes tradições educacionais e suas respectivas concepções sobre a qualidade da educação, podemos perceber que as mesmas trazem diferentes idéias e características sobre ensino, aprendizagem, ideologia, epistemologia, metodologia, estrutura disciplinar, objetivos individuais e sociais (TAVARES, 2013).

A abordagem Humanista-Construtivista destaca uma visão de que a natureza humana é boa, o comportamento é autônomo, a individualidade e a igualdade nascem com os seres humanos, sendo a desigualdade uma consequência das circunstâncias. Para os filósofos liberaishumanistas o aluno deveria ser o centro do processo educacional, numa concepção relativista sobre a qualidade da educação. A noção de aprendizagem individual ativa dos alunos proporcionou um elo entre Humanismo e o Construtivismo, em especial, de Dewey e Piaget; e recentemente com o chamado Construtivismo Social, sob influência de Vygotsky. 
Já, a abordagem Comportamentalista ou Behaviorista se opõe à visão Humanista, ao basear-se numa idéia de manipulação do comportamento através de estímulos (Skinner, Pavlov). Esta abordagem influenciou a reforma educacional da primeira metade do século passado. Defendiam o uso de pedagogias dedutivas, didáticas com exercícios de aprendizagem mecânica e memorização. Ainda hoje, podemos observar certos aspectos do behaviorismo nas práticas educativas atuais.

$\mathrm{Na}$ abordagem crítica, surgiram críticas ao Humanismo e ao Behaviorismo, na qual perceberam a sociedade como um sistema inter-relacional de valores (Parsons, Durkheim). A qualidade da educação estaria relacionada ao processo de transmissão destes valores. No final do século XX, os críticos reconheceram o aspecto político daquele processo. Neomarxistas (Bourdieu, Passeron) entenderam a educação como reprodutora e legitimadora das desigualdades sociais advindas da sociedade capitalista. $O$ grupo dos desescolarizadores defendeu uma educação formal organizada pelas comunidades, ou seja, uma sociedade sem escolas (Illich). Ainda se destacariam os críticos pós-modernistas (ou pós-estruturalistas, Foucault). Todos estes grupos compartilhavam a abordagem crítica da educação como reprodutora das desigualdades sociais, questionando que uma escolarização universal desenvolva, automaticamente, igualmente o potencial dos alunos. Desta forma, surgiu uma pedagogia crítica emancipatória (Freire, Giroux, Mclaren) sugerindo que os intelectuais críticos se dedicassem para a educação dos marginalizados, ajudando a diminuir as desigualdades sociais.

A abordagem nativa-indígena nasceu das visões educacionais alternativas em países pobres e marcados pelo colonialismo (Ghandi, Nyerere), na qual destacavam a relevância cultural da autoconfiança, da equidade e do emprego rural. Essa abordagem cultural nativa desafiou os conhecimentos curriculares dominantes (como exemplo, citamos a Etnomatemática).

Por fim, a abordagem para a educação de adultos, sempre preterida nos debates sobre a qualidade da educação, é composta por aspectos behavioristas, humanistas e críticos. Alguns influenciados pelo Humanismo e pelo Construtivismo exaltam a experiência dos adultos como base para sua aprendizagem; outros colocam a educação de adultos como fator essencial para qualquer transformação social, cultural, política e histórica (o exemplo que podemos indicar, no caso, é Paulo Freire).

As concepções teóricas sobre a qualidade da educação explicitadas na obra intitulada "Educação de Qualidade Para Todos: um assunto de direitos humanos" (2008), é importante para o desenvolvimento do trabalho:

Partindo do consenso de que "a educação é um direito humano fundamental e um bem público inalienável", o Escritório Regional de Educação da UNESCO para a América Latina e - Caribe (OREALC/UNESCO Santiago) propõe uma primeira aproximação do que é qualidade da educação. A concebe como um meio para que o ser humano se desenvolva plenamente como tal, já que graças a ela cresce e se fortalece como indivíduo e como espécie que contribui para o desenvolvimento da sociedade, transmitindo e compartilhando seus valores e sua cultura. A educação é, portanto, um processo permanente que facilita a aprendizagem, o desenvolvimento de competências, a 
experiência e a incorporação plena dos valores, afetos e de suas potencialidades, tanto individuais como sociais. Assim, tem um valor em si mesma e não apenas como ferramenta para o crescimento econômico e o desenvolvimento social. A missão da educação é o desenvolvimento integral de cidadãos que também sejam capazes de transformar a sociedade atual, tornando-a mais justa, inclusiva e democrática, mais do que a formação de sujeitos capazes de se integrar e 'funcionar adequadamente' nela. Sobre esta base, a OREALC/UNESCO Santiago propõe um conceito de qualidade da educação formado por cinco dimensões essenciais e estreitamente ligadas, ao ponto de que a ausência de alguma implicaria uma concepção errada da qualidade da educação dentro de uma abordagem de direitos humanos. Estas cinco dimensões são equidade, relevância, pertinência, eficácia e eficiência. Conhecê-las e incorporá-las é o que permite abordar de uma maneira mais bemsucedida para a avaliação da mesma. (p. 06-07). ${ }^{5}$

Na visão da OREALC/UNESCO Santiago, o que define uma educação de qualidade para todos é o conjunto das dimensões de equidade, relevância, pertinência, eficácia e eficiência. A evolução da qualidade deve se basear numa visão do conjunto destas dimensões.

A equidade busca oferecer todos os recursos e ajudas para toda a diversidade de alunos, de acordo com suas capacidades, para o desenvolvimento das competências necessárias à sua vida social. Qualidade e equidade são indissociáveis, garantindo tanto a igualdade como a diferenciação. O conhecimento, os recursos e as condições para o desenvolvimento das competências necessárias para o exercício da cidadania se inserem na sociedade do conhecimento atual, com emprego digno e liberdade. Estas referências trazem consigo a visão da pedagogia das competências (SAVIANI, 2008, p. 437).

Equidade e igualdade, ainda que relacionados, suas interpenetrações têm respaldado o tratamento homogêneo a todos e o aprofundamento das desigualdades. A evocação da equidade, ao invés da igualdade, proporciona que certas desigualdades devem ser levadas em conta, garantindo uma igualdade de oportunidades por meio de maiores recursos para os mais vulneráveis.

A relevância está ligada às finalidades da educação ao conjunto de uma determinada sociedade. Isto refere-se à uma aprendizagem significativa pessoal e social, levando em conta o

\footnotetext{
${ }^{5}$ Partiendo del consenso de que "la educación es un derecho humano fundamental y um bien público irrenunciable" 3 , la Oficina Regional de Educación de la UNESCO para América Latina y el Caribe (OREALC/UNESCO Santiago) propone una primera aproximación de lo que es calidad de la educación. La concibe como un medio para que el ser humano se desarrolle plenamente como tal, ya que gracias a ella crece y se fortalece como persona y como especie que contribuye al desarrollo de la sociedad, transmitiendo y compartiendo sus valores y su cultura. [...] La educación es, por tanto, un proceso permanente que facilita el aprendizaje, el desarrollo de competencias, la experiencia y la incorporación plena de los valores, afectos y de sus potencialidades, tanto individuales como sociales. Así, tiene un valor en sí misma y no únicamente como herramienta para el crecimiento económico o el desarrollo social. La misión de la educación es el desarrollo integral de ciudadanos que también sean capaces de transformar la sociedad actual, haciéndola más justa, inclusiva y democrática, más que la formación de sujetos capaces de integrarse y 'funcionar adecuadamente' en ella. Sobre esta base, la OREALC/UNESCO Santiago plantea un concepto de calidad de la educación conformado por cinco dimensiones esenciales y estrechamente imbricadas, al punto que la ausencia de alguna implicaría una concepción equivocada de la calidad de la educación dentro de un enfoque de derechos humanos4. Estas cinco dimensiones son equidad, relevancia, pertinencia, eficacia y eficiencia. Conocerlas e incorporarlas es lo que permitirá abordar de una manera más acertada la evaluación de la misma. (p. 06-07).
} 
contexto histórico, social e culturalmente determinado. A finalidade principal da educação é o pleno desenvolvimento do ser humano.

A pertinência refere-se à necessidade de uma educação significativa para as pessoas de todas as classes sociais, colocando o aluno como centro da educação. Desta forma, a educação deve se adaptar e ser flexível no tempo, no currículo e na frequência escolar, de acordo com as características e necessidades dos alunos dos mais diversos contextos socioculturais.

A eficácia destaca a proporção e à medida que são atendidos os objetivos da educação. Em termos de direitos humanos fundamentais, atende as necessidades de todos os estudantes, com aprendizagens relevantes e pertinentes e busca alcançar as metas educativas por parte de todos, diminuindo as desigualdades sociais.

A eficiência trata dos custos empregados para alcançar os objetivos da educação; relacionando seu financiamento, responsabilidade de aplicação, modelo de gestão e o uso dos recursos. Isto garante que os recursos públicos destinados pela sociedade à educação sejam investidos de forma eficiente. Porém, a eficiência não pode ser reduzida a uma visão economicista. A interação entre eficácia e eficiência garante que as desigualdades e as exclusões sociais não sejam reproduzidas.

As "Reflexiones en torno a la evalución de la calidad educativa em América Latina y el Caribe" (2008) são de grande riqueza teórico-metodológica, fornecendo valiosas contribuições para a nossa investigação sobre as concepções sobre a qualidade da educação na América Latina.

Martinic (2008) em seu artigo “Información, participación y enfoque de derechos" alertava que não podemos reduzir a evolução da qualidade educacional a uma simples medição ou a uma qualificação solitária do desempenho dos alunos pelo professor em sala de aula. Para o autor, a não consideração das heterogeneidades escolares pelas avaliações estandardizadas (em larga escala) reforçam ou criam uma discriminação social.

Os testes não podem resolver as desigualdades, mas sim legitima-las. Como assinala Reimers (2002) uma ordem desigual e excludente pode adquirir legitimidade graças a um sistema de avaliação e medição que cria a impressão de que a desigualdade é resultado de diferenças nos méritos e esforços das pessoas, e não de condições sobre as quais elas não podem exercer o controle. (MARTINIC, 2008, p. 20). ${ }^{6}$

Martinic (2008) reafirmou ainda, a constatação feita por Risopátron, em 1991, de que teoria predominante nas avaliações das evoluções da qualidade da educação seguia sendo a positivista:

\footnotetext{
${ }^{6}$ Las pruebas no pueden resolver las desigualdades; pero sí legitimarlas. Como señala Reimers (2002) un orden desigual y excluyente puede adquirir legitimidad gracias a un sistema de evaluación y de medición que crea la impresión de que la desigualdad es resultado de diferencias en los méritos y esfuerzos de las personas, y no de condiciones sobre las que ellas no pueden ejercer control. (MARTINIC, 2008, p. 20).
} 
O paradigma que tem dominado as avaliações é inspirado no positivismo: a avaliação mede o cumprimento de metas e o estudo, por excelência, é o experimental. Do ponto de vista teórico, os resultados das políticas são explicados, em grande parte, por fatores de contexto; e a aprendizagem dos estudantes, por variáveis que respondem ao behaviorismo. $^{7}$

Ele defende uma mudança da teoria positivista externa às escolas para outra baseada na realidade escolar interna, no caso: a construtivista. Destacando ainda que uma definição sobre a qualidade da educação dependerá do ponto-de-vista teórico utilizado.

Poggi, no seu trabalho: "Hacia la construcción de nuevas estrategias de evaluación de la calidad educativa en América Latina" (2008) buscou algumas definições sobre qualidade da educação:

Em primeiro lugar, é importante ter presente a definição de qualidade proposta pela OREALC/UNESCO Santiago: "A qualidade da educação, enquanto direito fundamental, além de ser eficaz e eficiente, deve respeitar os direitos de todas as pessoas, ser relevante, pertinente e equitativa. Exercer o direito à educação é essencial para desenvolver a personalidade e implementar os outros direitos. (OREALC/UNESCO Santiago, 2007a apud POGGI, 2008, p. 37). ${ }^{8}$

\section{Esclarecendo adiante que:}

Tanto a redução da qualidade para uma perspectiva exclusivamente eficientista como a concepção restrita da relevância estão vinculadas com duas questões centrais sobre as quais alerta o documento citado da OREALC/UNESCO Santiago, na relação com o fato de definir a qualidade da educação só para os resultados de aprendizagem em certas áreas. Como já foi mencionado anteriormente, surge o risco do reducionismo instrumental, o que pressupõe entender a qualidade que apenas a partir dos aspectos mensuráveis através de testes padronizadas. A principal consequência deste viés é o esquecimento ou desprezo de aprendizagem de vital importância, que dificilmente podem ser avaliados com essas ferramentas. Se em contextos onde prima o reducionismo instrumental fossem implementadas políticas baseadas em incentivos ligados com os resultados de testes padronizados, existe o risco de empobrecer o sentido da educação, em particular nas áreas curriculares mais afastadas das medições; mas que contemplam aprendizagens essenciais para o desenvolvimento integral das pessoas e das sociedades. Este aspecto levanta,

\footnotetext{
${ }^{7}$ El paradigma que ha predominado en las evaluaciones está inspirado en el positivismo: la evaluación mide el cumplimiento de objetivos y el estudio, por excelencia, es el experimental. Desde el punto de vista teórico, los resultados de las políticas quedan explicados, en gran parte, por los factores de contexto; y el aprendizaje de los estudiantes, por variables que responden al conductismo. (SHEPARD, 2000; TYLOR y LYONS, 1996 apud MARTINIC, 2008, p.25). ${ }^{8}$ En primer lugar, es importante tener presente la definición de calidad propuesta por OREALC/UNESCO Santiago: "La calidad de la educación en tanto derecho fundamental, además de ser eficaz y eficiente, debe respetar los derechos de todas las personas, ser relevante, pertinente y equitativa. Ejercer el derecho a la educación es esencial para desarrollar la personalidad e implementar los otros derechos . (OREALC/UNESCO Santiago, 2007 apud POGGI, 2008, p. 37).
} 
especialmente, o desafio de gerar práticas avaliativas mais compreensivas. (POGGI, 2008, p. 39). ${ }^{9}$

Cuéllar (2008) em "Reflexiónes desde la experiência mexicana em evalución educativa" foi taxativa ao dizer que se desejamos medi-lá, primeiro temos que entender o que é qualidade da educação. E sobre a medição da aprendizagem dos alunos nas avaliações em larga escala como representação da qualidade da educação, também concorda com Martinic (2008), ao dizer: “ [...] não se pode reduzir-se a qualidade da educação aos resultados das provas, e que uma avaliação seja informação fundamental para a qualidade da educação, pois não é um indicador completo da mesma". (GTEE, 2007, p. 05 apud CUÉLLAR, 2008, p. 54)..$^{10}$

Destacando mais adiante, que:

[...] é importante mencionar a importância de combinar as avaliações nacionais padronizadas, que oferecem um olhar sobre o conjunto do sistema, com a realização de estudos qualitativos que permitam aprofundar os processos escolares e os processos que ocorrem em sala de aula. Esta combinação de abordagens é a melhor forma de fornecer informação rica e complexa, para pensar nas políticas educacionais e nas práticas de ensino. (GTEE, 2007, p. 20 apud CUÉLLAR, 2008, p. 61). ${ }^{11}$

Valdes (2008), em "Hacia una evalución del desarrollo y formación corporal, racional y emocional del ser humano: o caso de Cuba", desde o nosso horizonte teórico, desenvolveu um trabalho filosófico e metodológico consistente sobre a qualidade da educação. Ele iniciou definindo que cada ser humano possui as dimensões: corporal, racional e emocional. Então, a educação deve desenvolver harmoniosamente e integralmente àquelas dimensões; e assim, um bom sistema de evolução da qualidade da educação deveria ter este enfoque holístico. E sacramentou que: "A qualidade da educação é prioritariamente um problema social e político - e

\footnotetext{
${ }^{9}$ Tanto la reducción de la calidad a una perspectiva exclusivamente eficientista como la concepción restringida de la relevancia están vinculadas con dos cuestiones centrales sobre las que alerta el documento citado de la OREALC/UNESCO Santiago, en relación con el hecho de definir la calidad de la educación solamente por los resultados de aprendizaje en determinadas áreas. Como ya fue mencionado anteriormente, surge el riesgo del reduccionismo instrumental, que supone entender la calidad sólo a partir de aquellos aspectos mensurables mediante pruebas estandarizadas. La principal consecuencia de este sesgo es el olvido o desprecio de aprendizajes de vital importancia, que difícilmente pueden evaluarse con estas herramientas. Si en contextos donde prima el reduccionismo instrumental fueran implementadas políticas basadas en incentivos ligados con los resultados de pruebas estandarizadas, existe el riesgo de empobrecer el sentido de la educación, en particular en las áreas curriculares más alejadas de las mediciones; pero que contemplan aprendizajes esenciales para el desarrollo integral de las personas y de lãs sociedades. Este aspecto plantea, especialmente, el desafío de generar prácticas evaluativas más compreensivas (POGGI, 2008, p. 39).

10 “'[...] no puede reducirse la 'calidad educativa' a los resultados de las pruebas, y que una evaluación estandarizada aporta información fundamental sobre la "calidad educativa', pero no es um indicador completo de la misma"

${ }^{11}[\ldots]$ es importante mencionar la importancia de combinar las evaluaciones nacionales estandarizadas, que ofrecen una mirada sobre el conjunto del sistema, con la realización de estudios cualitativos que permitan profundizar en los procesos escolares y los procesos que ocurren en las aulas. Esta combinación de enfoques es el mejor modo de aportar información rica y compleja para pensar en las políticas educativas y en las prácticas de enseñanza. (GTEE, 2007, p. 20 apud CUÉLLAR, 2008, p. 61).
} 
não apenas pedagógico e técnico - pois é improvável encontrar uma definição universalmente consensual". (VALDES, 2008, p. 71). ${ }^{12}$

O autor cubano relatou a existência de três concepções teóricas sobre qualidade da educação:

Uma análise minuciosa da literatura disponível em Cuba, e em outros dez países latinoamericanos, sobre o tratamento dado ao conceito de qualidade da educação, leva-nos à conclusão de que, em geral, existem três tendências claramente diferenciadas ao abordálo: uma procura discuti-la e defini-la de forma constitutiva, ou conceitual, ou seja, defini-la teoricamente. A segunda trata de definir operacionalmente, por meio de um conjunto de indicadores; e a terceira começa a defini-la. (VALDES, 2008, p. 71-72). ${ }^{13}$

Para Valdes (2008), a definição de qualidade como um adjetivo da educação consiste num equívoco filosófico, partindo da premissa que todos os objetos têm uma qualidade; visto que tal definição admitiria ser possível a existência de uma educação sem qualidade, e que seria filosoficamente impossível. Por outro lado, a quantidade da educação seria maior ou menor, na medida em que se aproxime ou se distancie dos paradigmas filosóficos, sociológicos, pedagógicos, psicológicos de uma sociedade histórico-concreta.

Uma primeira tendência busca definir teoricamente a qualidade da educação. Nesta, coexistem subtendências, sendo que a principal tem definições centradas no processo ou no produto; e a maior parte relaciona qualidade com os resultados escolares. Valdes discorda desta ideia: "Nós entendemos a qualidade da educação, como tendência, como trajetória, como um processo de construção contínuo e aperfeiçoamento eterno dos produtos". (2008, p. 73). ${ }^{14}$

Noutra subtendência, podemos encontrar concepções sobre a qualidade da educação centradas num dos elementos do processo de ensino-aprendizagem como: currículo, aluno, professores, escolas, entre outros.

A atual concepção teórica sobre qualidade da educação predominante na UNESCO pode ser encontrada na segunda tendência, por ser de operacionalizada por meio de indicadores como: relevância, equidade, eficácia, eficiência e pertinência. $O$ destaque da terceira tendência sobre a qualidade educacional está justamente numa ambigüidade conceitual teórica, tida como a sua riqueza.

\footnotetext{
12 "La calidad de la educación es prioritariamente un problema social y político - y no solo pedagógico y técnico- por lo que resulta improbable encontrar una definición universalmente consensuada". (VALDES, 2008, p. 71).

${ }^{13}$ Un análisis minucioso de la literatura disponible en Cuba, y en otros diez países latinoamericanos, acerca del tratamiento dado al concepto de calidad de la educación, nos lleva a la conclusión de que, en general, existen tres tendencias claramente diferenciadas al abordarlo: una procura discutirlo y definirlo en forma constitutiva o conceptual; es decir, definirlo teóricamente. La segunda trata de definirlo operacionalmente, por medio de un conjunto de indicadores; y la tercera elude definirlo. (VALDES, 2008, p. 71-72).

14 "Nosotros entendemos la calidad de la educación como tendencia, como trayectoria, como proceso de construcción continuo y como perfeccionamiento eterno de los produtos". (2008, p. 73).
} 
Definindo a qualidade da educação em Cuba, Valdes (2008, p. 76), diz que a:

Qualidade da educação refere-se às características do contexto, insumos, processos e resultados da formação do ser humano. Está condicionada histórica e socialmente e toma uma expressão concreta a partir do ideário filosófico, pedagógico, sociológico e psicológico predominante em uma sociedade determinada. É medida pela distância existente entre a norma (o ideal) e o dado (o que realmente ocorre na prática educativa). Esse ideário se concretiza no fim e cos os objetivos da educação. ${ }^{15}$

O autor destaca que a educação cubana se sustenta filosoficamente no marxismo conjugado nacionalmente com o ideário de Martí; e na psicologia histórico-cultural de Vygotsky e desenvolvida pela psicologia soviética, essencialmente humanista na ontologia marxista. Elenca os seguintes critérios operacionais para avaliar a qualidade da educação, em Cuba: o caráter universal da educação como direito de todos os seres humanos; a necessária unidade entre ensino e educação; e a necessária integração de variáveis: contexto, insumo, processo e produto. No julgamento da qualidade da educação, o autor cubano entende que precisamos de índices quantitativos e qualitativos e modelos de análises lineares e não-lineares.

Definimos, então, o que é para nós avaliar a qualidade da educação: é um processo sistemático de obtenção de dados válidos e confiáveis sobre o contexto, os recursos, os processos e os resultados da educação, constatando, assim, a natureza da prática educativa para compará-la com o ideal consubstanciado na finalidade e os objetivos da mesma, especificando as diferenças entre ambos e suas possíveis causas. Se entendermos, e nós somos consequentes com a definição acima, podemos concluir que, em nossa região até o momento não temos avaliado a $\mathrm{CE}$, pois as ações deste tipo comumente realizadas têm resultado em 'fotografias' de um momento do desenvolvimento do ciclo escolar em questão; e não uma avaliação sistemática, permanente, do desempenho de gestores, professores. (VALDES, 2008, p. 82). ${ }^{16}$

\footnotetext{
${ }^{15}$ Calidad de la educación se refiere a las características del contexto, insumos, procesos y resultados de la formación del ser humano. Está condicionada histórica y socialmente y toma uma expresión concreta a partir del ideario filosófico, pedagógico, sociológico y psicológico imperante em una sociedad determinada. Es medida por la distancia existente entre la norma (el ideario) y el dato (lo que ocurre realmente en la práctica educativa). Ese ideario se concreta en el fin y los objetivos de la educación. (VALDES, 2008, p. 76).

${ }^{16}$ Definamos, entonces, qué es para nosotros evaluar la calidad de la educación: es un proceso sistemático de obtención de datos válidos y fiables acerca del contexto, los recursos, los procesos y los resultados de la educación, constatando así la naturaleza de la práctica educativa para compararla con el ideal plasmado en el fin y los objetivos de la misma, precisando las diferencias entre ambos y sus posibles causas. Si comprendemos, y somos consecuentes, con la definición anterior podemos concluir que en nuestra región hasta el momento no hemos evaluado la CE, pues las acciones de este tipo comúnmente realizadas han resultado 'fotografías' de un momento del desarrollo del ciclo escolar en cuestión; y no una valoración sistemática, permanente, del desempeño de directivos, docentes. (VALDES, 2008, p. 82).
} 
Valdes ainda sugere algumas ideias para planejamento e execução da evolução da qualidade da educação na América Latina e Caribe como: se queres medir a mudança, não mude a medida; passar de uma avaliação centrada nos resultados para uma que examina, prioritariamente, o estado dos processos; direcionar para um treinamento na autoevolução dos professores; ir do sistema avaliativo de amostragem aos de censo; uso de métodos experimentais para o controle das variáveis das políticas educativas; estas não devem centrar-se só no rendimento escolar dos alunos e sim levar em conta o desenvolvimento pessoal e profissional dos diferentes agentes educativos (alunos, professores, pais); de uma evolução de caráter absoluto a uma de caráter relativo.

Ao finalizar sua reflexão, Valdes salientou que o rendimento escolar não pode ser o único foco das avaliações da qualidade da educação, e que precisamos buscar um enfoque mais integral do ser humano, que leve em conta as suas dimensões corporais, racionais e emocionais.

\section{ALGUMAS CONSIDERAÇÕES}

Podemos evidenciar a existência de diversas concepções teóricas sobre a qualidade da educação na América Latina. A maioria delas ainda tem no positivismo sua base teóricometodológica. Podemos constatar nas publicações da UNESCO e dos seus órgãos regionais, as influências dos paradigmas positivista, do comportamentalista-behaviorista e da pedagogia das competências, preferindo uma concepção sobre a qualidade da educação através de uma forma operacional (de dimensões) e de indicadores.

Constatamos, também, que a maior parte das concepções teóricas sobre a qualidade educacional latino-americana prescinde de uma base filosófica na sua definição conceitual. Concordamos com Valdes, defensor de que a definição teórica de qualidade da educação deva ser, prioritariamente, um problema social e político, e não somente pedagógico e técnico; o que quase inviabiliza uma categorização universal ou consensual da mesma, uma vez que, lutamos por uma educação socializante em oposição ao modelo educacional privatizante.

Nesta exposição, podemos ter uma pequena amostragem da complexidade envolvida nas definições de concepções teóricas sobre a qualidade da educação na América Latina. De outro lado, almejamos contribuir para um debate sobre a necessidade da construção de uma concepção teórica sobre a qualidade da educação, que leve em conta a integralidade do ser humano: corporal, racional e emocional, e que também possa se inserir num amplo projeto histórico-social, mais humanista e solidário, para a nossa sociedade. 


\section{REFERÊNCIAS}

ANDERSON, P. Balanço do Neoliberalismo. (1995). In Pós-neoliberalismo. As políticas sociais e o Estado democrático. Emir Sader \& Pablo Gentili (orgs.) Rio de Janeiro : Paz e Terra,.

CHINAPH, V. (2000). Rendimento e Aprendizagem: construção de competencias. Campinas, São Paulo : Autores Associados, Brasília: UNESCO.

CUÉLLAR, G. R. (2008). Reflexiónes Desde la Experiência Mexicana em Evalución Educativa. In: Reflexiones en Torno a la Evaluación de la Calidad Educativa en América Latina y el Caribe. Santiago/Chile: Oficina Regional de Educación de la UNESCO para América Latina y el Caribe (OREALC/UNESCO Santiago) y el Laboratorio Latinoamericano de Evaluación de la Calidad de la Educación (LLECE), septiembre, p. 49-66.

DELORS, J. (2001). Educação: um tesouro a descobrir. Relatório para a UNESCO da Comissão Internacional sobre Educação para o século XXI. São Paulo: Cortez.

GENTILI, P. (2009). O Direito à Educação e as Dinâmicas de Exclusão na América Latina. Educação e Sociedade, vol. 30, no 109, São Paulo: Cortez; Campinas: Cedes, p. 1059-1079.

GORENDER, J. (1995). Estratégias dos Estados Nacionais Diante do Processo de Globalização. Revista de Estudos Avançados da USP. São Paulo, no 9 (25).

MARTINIC, S. (2008) Información, participación y enfoque de derechos. In: Reflexiones en Torno a la Evaluación de la Calidad Educativa en América Latina y el Caribe. Santiago/Chile: Oficina Regional de Educación de la UNESCO para América Latina y el Caribe (OREALC/UNESCO Santiago) y el Laboratorio Latinoamericano de Evaluación de la Calidad de la Educación (LLECE), septiembre, p. 13-34.

POGGI, M. (2008). Hacia la construcción de nuevas estrategias de evaluación de la alidad educativa en América Latina. In: Reflexiones en Torno a la Evaluación de la Calidad Educativa en América Latina y el Caribe. Santiago/Chile: Oficina Regional de Educación de la UNESCO para América Latina y el Caribe (OREALC/UNESCO Santiago) y el Laboratorio Latinoamericano de Evaluación de la Calidad de la Educación (LLECE), septiembre, p. 35-48.

UNESCO. (2008). Reflexiones en torno a la evaluación de la calidad educativa en América Latina y el Caribe. Santiago, Chile: Oficina Regional de Educación de la UNESCO para América Latina y el Caribe (OREALC/UNESCO Santiago) y el Laboratorio Latinoamericano de Evaluación de la Calidad de la Educación (LLECE), 2008.

RISOPATRÓN, V. E. (1991). El Concepto de Calidad de la Educacion. Santiago, Chile: UNESCO/OREALC.

SAVIANI, D. (2008). História das Ideias Pedagógicas no Brasil. Campinas/SP: Autores Associados.

UNESCO. (2007). Situación Educativa de América Latina y el Caribe: garantizando la Educación de Calidad para Todos. Informe Regional de Revisión y Evaluación del Progreso de América Latina y el Caribe hacia la Educación para Todos en el marco del Proyecto Regional de 
Educación (EPT/PRELAC). Santiago, Chile: Oficina Regional de Educación de la UNESCO para América Latina y el Caribe (OREALC/UNESCO Santiago) y el Laboratorio Latinoamericano de Evaluación de la Calidad de la Educación (LLECE), 2007.

TAVARES, E. L. H. (2013). Avaliação em Larga Escala e Qualidade da Educação: um estudo a partir da visão dos sujeitos da Rede Escolar Municipal De Cachoeirinha/RS. 2013, 209 f. Dossertação (Mestrado em Educação) - Programa de Pós-Graduação em Educação, Universidade do Vale do Rio dos Sinos (UNISINOS).

UNESCO, OREALC. (2008). Educação de Qualidade Para Todos: um assunto de direitos humanos. 2.ed. Brasília.

UNESCO, OREALC. (1998). Declaração Mundial sobre Educação para Todos: satisfação das necessidades básicas de aprendizagem, Jomtien, 1990. Disponível em <http://unesdoc.UNESCO.org/images/0008/000862/086291por.pdf.[11_abr._2011].

UNESCO, OREALC. (2011). Educação Para Todos: o compromisso de Dakar. Brasília: UNESCO, CONSED, Ação Educativa.

UNESCO, OREALC. (1966). Educación y Desarrollo en América Latina - Bases para una Política Educativa. Buenos Aires: Solar/Hachete.

UNESCO, OREALC. (1974). Educar Para o Futuro. Rio de Janeiro: Fundação Getúlio Vargas.

UNESCO, OREALC. (1991). Informe mundial sobre la educación. Santillana/UNESCO.

UNESCO, OREALC. (2005). Relatório de Monitoramento Global de EPT 2005: educação para todos - o imperativo da qualidade. Tradução B\&C Revisão de Textos S/C Ltda. São Paulo: Moderna.

VALDES, H. (2008). Hacia una evalución del desarrollo y formación corporal, racional y emocional del ser humano: o caso de Cuba. In: Reflexiones en torno a la evaluación de la calidad educativa en América Latina y el Caribe. Publicado por la Oficina Regional de Educación de la UNESCO para América Latina y el Caribe (OREALC/UNESCO Santiago) y el Laboratorio Latinoamericano de Evaluación de la Calidad de la Educación (LLECE). Santiago, Chile; septiembre, p. 67-90. 